\title{
ARRANJOS FAMILIARES DE CRIANÇAS DAS CAMADAS POPULARES ${ }^{1}$
}

\author{
Maria Cristina Lopes de Almeida Amazonas \\ Prisciany Ramos Damasceno \\ Luisa de Marilak de Souza Terto \\ Renata Raimundo da Silva
}

\begin{abstract}
RESUMO. Esta pesquisa estudou o funcionamento e os arranjos familiares de crianças de uma escola pública da cidade do Recife. A amostra se constituiu de 100 pessoas, sendo 50 adultos (pais ou responsáveis pelas crianças) e 50 crianças de 06 a 11 anos. Foram utilizados como instrumento a Entrevista do Genograma e o Desenho da Família com Estória. Os resultados mostram vários tipos de arranjos familiares entre estas crianças, predominando a família nuclear. Quanto ao funcionamento, a maioria dessas famílias se organiza em torno de mulheres, sendo as figuras masculinas fragilizadas pelo desemprego, uso de álcool ou outras drogas.
\end{abstract}

Palavras-chave: família, criança, arranjo familiar.

\section{FAMILY ARRANGEMENTS FOR CHILDREN IN A LOW-INCOME GROUP}

\begin{abstract}
This research was regarding family functioning and ways of dealing with low income family children from a public school in the city of Recife. The sample consisted of 100 people of both sexes (parents and children caretakers) from 25 to 55 years of age. The instrument used was the Genogram Interview and Family Drawing with Story Telling. The results show that there are many types of family arrangements for taking care of these children, being the most common, the nuclear one. As for the family functioning, the great majority follows the female leadership due to the fragile role played by the male figure, who is frequently associated to unemployment and addiction to drugs.
\end{abstract}

Key words: family; family arrangement; child care.

\section{INTRODUÇÃO}

A família é o principal agente da socialização e reproduz padrões culturais no indivíduo. Ela "inculca modos de pensar e atuar que se transformam em hábitos" (Lasch, 1991, p.25). É na família que se concentram as possibilidades de constituição de pessoas enquanto sujeitos e cidadãos. É no seio dela que vão acontecer as primeiras identificações, espelho para identificações futuras. Considerando a importância da família enquanto principal doadora de identidade e responsável pela produção de comportamentos é que resolvemos investigar como algumas famílias das camadas populares da cidade do
Recife se organizam, quais os tipos de arranjos presentes entre elas e quais as formas de funcionamento adotadas. A literatura sobre este tipo de família é ampla, porém são poucos os estudos realizados em nossa região. Nesta pesquisa, nossa intenção foi realizar um levantamento inicial, que nos fornecesse informações para um estudo mais amplo.

Entendemos por arranjo familiar os membros da família, consangüíneos ou não, residentes no mesmo domicílio. Quanto à forma de funcionamento da família, consideramos que abrange os motivos que o viabilizam, as relações hierárquicas estabelecidas com relação ao poder, as relações afetivas, a organização e o desempenho dos papéis familiares (Berthoud, 1997).

1 Apoio, Programas de Iniciação Científica da Unicap e da Facepe/CNPq. Foi apresentada nas Jornadas de Iniciação Científica das duas instituições e foi trabalho premiado da área de Ciências Humanas na Jornada de Iniciação Científica da Facepe/CNPq

* Professora-Doutora do Mestrado em Psicologia Clínica e da Graduação em Psicologia da Universidade Católica de Pernambuco - Unicap.

Endereço para correspondência: Rua do Futuro, 77, apto 1201, Graças, Recife-PE. E-mail: crisamaz@elogica.com.br

\# Bolsista de Iniciação Científica da Universidade Católica de Pernambuco - Unicap.

Il Bolsista de Iniciação Científica pela Fundação de Amparo à Ciência e Tecnologia do Estado de Pernambuco - Facepe/CNPq. 
As formas de estabelecer vínculos entre os seres humanos variam enormemente, tanto de uma época para outra quanto na mesma época, porém em lugares diferentes. Assim, a diversidade das formas de convivência humana não é privilégio de nossa época. No entanto, na contemporaneidade observa-se uma verdadeira revolução "no modo como pensamos sobre nós mesmos e no modo como formamos laços e ligações com outros" (Giddens, 2000, p.61). Convivemos com diversas formas vinculares, nenhuma necessariamente melhor ou pior que as outras. Ao lado de formas tidas como tradicionais, por exemplo, o tipo de família nuclear, há outras constituídas por casais homossexuais, monoparentais, recasados e tantas outras. É um verdadeiro contingente da diversidade! Não sabemos ainda quais serão as vantagens ou desvantagens que cada uma delas acarretará para o ser humano, principalmente para as crianças, uma vez que, por serem formas recentes, não permitem uma avaliação fundamentada. O que podemos dizer de todas essas transformações é que, apesar de tanta diversidade, ainda é grande a dificuldade que sentimos em aceitar as diferenças. A sociedade persiste na transmissão do modelo de família nuclear tradicional, com pai provedor e mãe donade-casa em tempo integral, como o ideal, e vê com maus olhos as novas configurações familiares.

De acordo com Giddens (2000), o que nos países ocidentais chamamos de família tradicional "é de fato uma fase tardia, transicional, que teve lugar no desenvolvimento da família na década de 1950" (p.66). Naquela época havia poucas mulheres que trabalhavam fora do lar e as separações conjugais eram vistas com preconceito. O casamento havia deixado de ter como base as relações econômicas e passado a se fundamentar na idéia de amor romântico. $\mathrm{Na}$ contemporaneidade as modificações socioeconômicas e culturais alteraram esses vínculos familiares. Os membros das famílias foram instados a assumir novos papéis e posições e levados a conviver com novos arranjos familiares. Os papéis destinados a cada sexo, antes fortemente delimitados, hoje se encontram mais flexibilizados. Na família tradicional atribuía-se ao pai a função de prover ao sustento do grupo familiar e à mãe as funções de responder pelos cuidados e afetos dedicados às crianças. Eram o pai e a mãe os responsáveis pela seleção, organização e construção das regras e valores passados aos filhos. Hoje, estas funções vêm sendo descentradas do núcleo tradicional. As crianças estão sendo entregues aos cuidados de tias, avós, babás, escolas, o que aumenta suas possibilidades de identificação.
A responsabilidade pela tranqüilidade do lar e os cuidados com os filhos, que eram consideradas tarefas das mulheres, estão sendo compartilhados por ambos os cônjuges. Mesmo quando o modelo é nuclear, o desempenho dos papéis já não é o mesmo de antes. Está aumentando o número de pais que cuidam dos filhos enquanto a mãe trabalha fora.

$O$ poder econômico do pai vem sendo enfraquecido, pois as mulheres estão reivindicando seu espaço no mercado de trabalho. Isto acontece tanto pela necessidade da família de aumentar a sua renda como pelas necessidades das mulheres de não restringirem sua vida ao âmbito do lar. O ideal de vida das mulheres atuais inclui a realização profissional.

Também os avanços tecnológicos influenciam a família. O controle da natalidade, a clonagem e a inseminação artificial estão provocando discussões sobre o que seja a família.

$\mathrm{E}$ as crianças, como se situam neste contexto? De acordo com Giddens (2000), "a posição das crianças em tudo isto é interessante e um tanto paradoxal. Nossas atitudes em relação às crianças e à sua proteção alteraram-se radicalmente ao longo de algumas gerações passadas"(p. 69). Como diz Ariès (1978), uma das conseqüências das transformações sociais que deram origem à família burguesa foi uma queda na mortalidade, principalmente a infantil; mas verificou-se também uma queda na natalidade. Como consequiência da grande diminuição do número de crianças, elas passaram a ser mais valorizadas. Além do mais, a decisão de ter filhos, com o avanço das técnicas contraceptivas e das transformações econômicas, é muito distinta daquilo que foi para gerações anteriores. Giddens (2000) diz:

na família tradicional, os filhos eram uma vantagem econômica. Hoje, nos países ocidentais, um filho, ao contrário, representa um grande encargo financeiro para os pais (p. 69).

\section{AS FAMÍLIAS DAS CAMADAS POPULARES}

Neste estudo, enfocamos o funcionamento das famílias das camadas populares. Consideramos que estas famílias ainda conservam algumas peculiaridades, apesar de viverem num mundo globalizado, numa sociedade onde o poder da mídia é excepcional, e apesar de terem sofrido transformações espetaculares, tendendo a aproximar-se do modelo familiar burguês. De modo geral, aspiram a corresponder aos modelos predominantes na sociedade, porém, tentam adequá-los às suas reais 
condições de existência. Poster (1979) nos ensina que a família da classe trabalhadora "desenvolveu uma estrutura de família sob condições de angústia social e econômica" (Poster,1979, p. 209). Duarte (1995) diz que a família de classe popular

conjuga a dimensão genérica do parentesco com a dimensão operacional do 'grupo doméstico' de modo a servir a essa reprodução estereotípica característica de todo o mundo social, à exceção daqueles permeados pela ideologia individualista. Ela se assemelha nesse sentido fortemente à família camponesa; em que pesem tantas e tão fortes diferenças dos contextos sociais em que se desenvolvem (p.34).

Dentre as diferenças que se observam nesse tipo de família, uma diz respeito ao papel desempenhado pelos filhos. Para essas famílias os filhos representam, muitas vezes, maior força de trabalho e ganhos econômicos, ao invés de despesas. Sobre este tipo de família Bilac (1995) afirma:

Uma família que se baseia na articulação entre o trabalho doméstico e o trabalho remunerado, mas que, reiterada, embora intermitentemente, termina por recorrer ao trabalho feminino remunerado e, dada à precariedade deste, ao trabalho das crianças e jovens, ao mesmo tempo em que busca prolongar a escolarização dos filhos (...) (p. 47).

Isto significa que as famílias das camadas populares, embora orientadas pelos ideais sociais vigentes em nossa época, terminam por fazer tentativas de conciliá-los com sua realidade de vida. Deste modo, estas organizações familiares, ainda que sofram a influência dos valores transmitidos pelas demais camadas da população, diferem significativamente delas, pois necessitam desenvolver estratégias de sobrevivência compatíveis com suas condições de existência.

No que tange ao modo de organização deste grupo familiar, Sarti (1995) diz:

A família entre os pobres urbanos é estruturada como um grupo hierárquico, seguindo um padrão de autoridade patriarcal, cujo princípio básico é a precedência do homem sobre a mulher, dos pais sobre os filhos e dos mais velhos sobre os mais novos. Em consonância com este modelo familiar, a organização doméstica é baseada no princípio da tradicional divisão sexual, em que o homem é o provedor e a mulher a dona-de-casa. Dentro deste modelo hierár- quico, os papéis familiares - de gênero e de idade - são definidos (...) (p.136).

Para Sarti, o modelo de família que se impõe para os brasileiros é o patriarcal. Afirma a autora que

o exercício dos papéis de gênero, nos casos
em que se desfaz a reciprocidade conjugal,
passa a ser alocada para a rede familiar mais
ampla (...) transferindo-os reiteradamente
para outras pessoas de mesmo sexo da rede
familiar (consangüínea ou afim) (Sarti, 1995,
p. 139).

Seguindo a orientação de Sarti, mesmo no caso da dissolução dos laços conjugais, as questões de gênero continuariam a prevalecer, para manter a tradição de homens provedores e mulheres cuidadoras dos filhos e maridos. É certo que essas posições de gênero persistem nas relações familiares ainda no momento atual, porém muito mais enquanto um ideal a ser perseguido do que uma realidade concreta. No cotidiano destas famílias essa divisão de trabalho por sexo não mais se sustenta, principalmente nas famílias das camadas populares, onde o trabalho feminino é vital para a existência e, aliado a outros fatores, como desemprego masculino, uso de álcool e outras drogas, seguramente enfraquece o poder do homem.

Isto significa que, concretamente, as famílias dessa população necessitam desenvolver estratégias de sobrevivência, e toda a rede familiar deve participar da manutenção do grupo, no que diz respeito tanto a prover materialmente quanto aos cuidados com seus membros, principalmente as crianças. Por isso promovem uma relação de solidariedade para, através do grupo, garantir a qualidade de vida de cada um. A lógica da solidariedade caracteriza a ação da família frente à sociedade e opõe-se à lógica do individualismo. Essa lógica reordena valores e subordina realizações pessoais a interesses ou necessidades do grupo familiar. A solidariedade é uma forma de a classe popular garantir a sua existência ante um contexto que oprime seu desenvolvimento. Esta solidariedade não se restringe ao grupo de parentes: muitas vezes é com a ajuda de um vizinho que toma conta das crianças que os pais conseguem sair para trabalhar e sustentar a família.

A lógica da solidariedade nem sempre pode ser interpretada como harmonia e consenso entre os membros da família, uma vez que é comum existirem nessas famílias casos de conflito, violência e agressividade. Ela se apresenta, sim, como uma maneira de proteger estas famílias e de possibilitar a sua sobrevivência na conjuntura socioeconômica. É, como afirma Bilac (1995) 
uma família sempre preocupada com o equilíbrio entre provedores e consumidores no núcleo familiar, ameaçada que é, continuamente, pelos salários arrochados e pelo desemprego, e que, por isso mesmo reforça a solidariedade entre seus membros e valoriza ao extremo a casa e a propriedade da casa. Por tudo isso, uma família que continuamente se organiza e se reorganiza, uma família que se estrutura e se reestrutura (p. 47)

Quanto aos arranjos familiares que prevalecem nesses grupos, Bilac diz que a família das camadas populares é "inicial e basicamente nuclear, mas que pode vir a se ampliar (...) para abrigar parentes ascendentes ou descendentes" (1995, p.47). Essa ampliação não se faz só com parentes, pois é também comum a presença de amigos e irmãos postiços. Muitas vezes, a coabitação decorre do fato de esse outro não ter onde morar, estar desempregado e precisar do auxílio da mãe, irmão, vizinho. Segundo Silveira, Falcke e Wagner (2000), o modelo dominante na família das camadas populares não é o nuclear, e sim, o monoparental. Estas famílias, em sua grande maioria, são chefiadas por mulheres. Isto pode ser um fator que acentua a centralidade da relação mãe-filho nestas famílias, já que a mulher tornou-se a provedora (Bilac, 1995). Antes as mães já estavam profundamente ligadas aos filhos, pois somente elas eram responsáveis pelos cuidados e afetos. Hoje, somada a estas funções está a tarefa de contribuir para o sustento do lar, ou mesmo de ser a única responsável por esse sustento. Isso acontece principalmente nas famílias monoparentais, mas também em casos onde o homem está desempregado, é alcoólatra, etc. As mulheres, agora, desempenham inúmeras funções na família e tornam-se peças-chave para sua organização e manutenção.

Outro aspecto interessante a ser discutido é a presença do modelo de família monoparental nas camadas populares. Nos casos destas famílias, a existência das famílias monoparentais pode não significar, necessariamente, a adoção de um modelo alternativo de relações familiares, mas também a impossibilidade de realização do modelo ideal: mãe em casa, pai no trabalho e criança na escola. Neste caso, as constantes e sucessivas uniões dessas mulheres, chamadas "monogamia seriada", podem significar um esforço para manter no lar a figura do provedor (Bilac, 1995).

Quanto à questão das relações hierárquicas e exercício do poder, o que se observa é que nestas famílias a hierarquização envolve relações de direitos e deveres que não atingem só o casal, mas se estendem aos demais consangüíneos. Essa ampliação dos direitos e deveres aos demais membros é importante devido à freqüente quebra dos vínculos conjugais (Sarti, 1995).

A concepção do exercício da autoridade na figura masculina leva a uma discussão sobre a mulher como chefe de família, visto ser crescente o papel econômico das mulheres nas famílias das camadas populares. Mesmo nos casos em que as mulheres são as provedoras, a noção do homem como figura de autoridade não se altera em todas as suas dimensões. É claro, porém, que ocorrem algumas modificações nas relações de autoridade. Por exemplo, se o homem não garante o lar e a comida da família, tem sua autoridade diminuída, o que acarreta uma fragilização da figura masculina. É na busca desse homem ideal como provedor que muitos casamentos ocorrem nessas famílias. A alternativa pode ser passar essa autoridade a um avô, tio, etc. (Sarti, 2003).

A dispersão dos papéis de gênero se dá pela impossibilidade de realizá-los numa só figura. Não é só o pai que, algumas vezes, não consegue exercer sua função tradicional, pois a figura feminina também nem sempre consegue ser mãe, dona-de-casa e esposa. Nestes casos enfatizam-se os vínculos com a rede familiar mais ampla, e até mesmo com a comunidade. Mais uma vez se volta à existência da solidariedade, constante nessas famílias. Começa-se a observar uma flutuação na ocupação dos lugares e papéis desempenhados (Sarti, 1995).

No caso do papel do provedor masculino, percebe-se que este pode ser inviabilizado a qualquer momento, seja por desemprego seja por alcoolismo ou doença. Vale salientar que o modelo tido como ideal continua sendo o tradicional, e é por isso que muitas dessas famílias tentam repeti-lo, mesmo ante a impossibilidade de sua realização prática.

Outro aspecto que chama a atenção nessas famílias é a indiferenciação entre o público e o privado. A rua torna-se um prolongamento da casa. As crianças convivem não só com o pai e a mãe, mas também com tios, avôs, madrinhas e vizinhos. Este fato, ao mesmo tempo que indica a necessidade dessa família de contar com a solidariedade da comunidade para garantir sua existência, apresenta como contraponto uma ampliação das possibilidades de identificação para as crianças, o que é muito importante para o processo de socialização delas.

As condições físicas da casa influenciam o prolongamento do lar para a rua. Habitações quentes, precárias, pequenas e desconfortáveis fazem com que estas famílias passem parte do seu tempo na rua e vivam muitas de suas experiências ali, junto com a comunidade. 


\section{MATERIAL E MÉTODOS}

\section{Participantes}

Esta pesquisa investigou os arranjos familiares e as formas de funcionamento das famílias de crianças de uma escola pública da cidade do Recife.

Desta investigação fizeram parte 100 sujeitos, sendo 50 crianças e 50 adultos. As crianças correspondiam a $15 \%$ das 330 da faixa etária de seis a onze anos que estudavam no turno da manhã da referida escola. Os adultos eram, preferencialmente, um de seus pais; na ausência de ambos, outro adulto que exercesse essas funções junto às crianças. As crianças foram selecionadas aleatoriamente e seus pais foram localizados a partir delas.

Para caracterizar o perfil da amostra, tomamos o conceito de camada social. Este conceito é desenvolvido por Quintas (2000). Para essa autora este conceito é mais conveniente do que o de classe social, que se apresenta mais monolítico. O conceito de camada social adapta-se melhor a certas peculiaridades, uma vez que adota indicadores dos tipos profissão, local e tipo de residência, escolaridade dos participantes, etc.

Deste modo nossa amostra foi caracterizada como de camada popular, tomando por base a escolaridade dos pais das crianças (no máximo o primeiro grau), suas profissões (mães - empregadas domésticas, faxineiras, diaristas; pais - vigias, zeladores, auxiliares de serviços gerais ou desempregados vivendo de biscates), o local e o tipo de moradia (favelas localizadas no meio de bairros de classe média, casa de alvenaria de um ou dois cômodos, ou ainda de tábuas ou outros materiais reaproveitados).

\section{Instrumentos}

Para identificar os arranjos familiares, utilizamos a Entrevista do Genograma, realizada com a mãe ou um responsável pela criança. A Entrevista do Genograma seguiu o roteiro de Mc Goldrick e Gerson (1987) citado por Freitas (1999). Neste estudo tomamos o conceito de grupo doméstico para identificar os arranjos familiares, isto é, consideramos um arranjo familiar os membros de uma família, consangüíneos ou não, residentes no mesmo domicílio. Isto não significa adotar um enfoque reducionista da família; não significa que igualemos família a grupo doméstico, mas, sim, que adotamos este conceito como uma estratégia de trabalho que possibilitasse a identificação dos arranjos familiares.

Não obstante, uma vez que nos interessava também o modo de funcionamento destas famílias, isto é, a dinâmica familiar, a concepção de família que adotamos neste estudo vai além da perspectiva concreta de grupo doméstico, pois inclui os aspectos sociais e simbólicos. Os aspectos sociais se referem ao campo das práticas sociais, e o simbólico diz respeito à linguagem, ao discurso, ao significado atribuído a essas práticas. Deste modo, outro instrumento que utilizamos para coletar os dados foi o Desenho da Família com Estórias (DF-E). Este foi aplicado às crianças e seguiu a orientação de Trinca (1997). De acordo com esse autor, o DF-E permite identificar os conflitos decorrentes das relações familiares e pontos expressivos de sua dinâmica. É um instrumento que se ajusta aos objetivos de nossa investigação, pois é especialmente útil como forma de expressão para as crianças, que se expressam melhor através de desenhos e de histórias. Deste modo, este instrumento permitiu a manifestação da estrutura e da dinâmica da família onde estas crianças estavam inseridas.

\section{Procedimento de coleta de dados}

O DF-E foi aplicado individualmente a cada criança e na própria escola. Aplicamos as quatro consignas sugeridas por Trinca (1997), quais sejam: desenho de uma família qualquer, desenho da família que gostaria de ter; desenho de uma família onde alguém não está bem e desenho de sua própria família. Com todas as crianças iniciamos pelo um desenho livre, e a cada desenho se seguia o relato de uma estória e atribuição de um título, assim como do inquérito. Todas as estórias foram gravadas e transcritas literalmente para a análise.

Após a aplicação do DF-E nas crianças, foi realizada a Entrevista do Genograma, preferencialmente com as mães delas, na própria escola ou na residência dos entrevistados, sempre em particular e individualmente. Quando não foi possível entrevistar a mãe da criança, entrevistamos outro responsável por ela. Do mesmo modo que as estórias do DF-E, as entrevistas foram gravadas em fita cassete e transcritas literalmente.

\section{Procedimento de análise dos dados}

Os dados foram submetidos à análise dos conteúdos orientada pelos objetivos da pesquisa. Inicialmente, adicionamos a cada conjunto de DF-E de uma criança a entrevista realizada com o adulto responsável. Cada conjunto formou um caso da análise. A análise das entrevistas serviu para identificar tanto os arranjos familiares quanto o modo de funcionamento da família. Para os arranjos familiares construímos representações gráficas do genograma de cada família entrevistada, e nomeamos o tipo de arranjo familiar frente aos dados surgidos no genograma. Apesar de o genograma permitir a visão 
de outras gerações familiares, para alcançar os objetivos propostos nesta pesquisa nos ativemos apenas a analisar a geração atual, tendo como ponto de referência a criança, chamada de pessoa-índice no genograma, com a preocupação de verificar quantas pessoas residem em seu ambiente familiar e o modo como se dispõem seus membros.

Para a análise do funcionamento da família seguimos as seguintes etapas: 1) leitura flutuante das entrevistas, com o fim de apreender o significado do todo e os temas que emergiam; 2) releitura das entrevistas, tentando identificar a freqüência com que cada tema aparecia.

Quanto aos DF-Es, observávamos nos desenhos e nas estórias o que elas comunicavam sobre a dinâmica das famílias, figuras reproduzidas e/ou ausentes, o tamanho dessas famílias, as figuras que vinham em primeiro lugar, etc. O DF-E não foi utilizado com fim diagnóstico, e sim, como um veículo de comunicação. Por fim, reunimos o conjunto das entrevistas e dos desenhos, observando o que eles tinham em comum em relação aos temas da análise, com o fim de compreender a dinâmica familiar das crianças em estudo.

\section{ANÁLISE E DISCUSSÃO DOS RESULTADOS}

$\mathrm{O}$ arranjo familiar predominante no todo da amostra foi o nuclear $(32,7 \%)$, seguido pelo de família extensa $(24,5 \%)$, de recasados $(16,3 \%)$, monoparental $(14,3 \%)$, adotiva $(8,2 \%)$ e abrangente $(4,1 \%)$.

Como podemos observar, apesar do predomínio da família nuclear sobre os demais modelos, há, nesta amostra, uma grande diversidade de tipos de arranjos familiares. Estes resultados vêm ao encontro do que aponta a literatura. Os estudos de Bilac (1995) nos informam que nas camadas populares a família é inicialmente nuclear, embora possa vir a se ampliar em certas fases de seu ciclo vital, abrigando parentes ascendentes ou descendentes. Isto se confirma quando fizemos a análise por faixa etária das crianças. $\mathrm{O}$ modelo de família nuclear predomina, principalmente, na faixa etária dos 06 a 07 anos $(35,7 \%)$ e se reduz à medida que aumenta a idade, chegando a $27 \%$ na faixa etária dos 10 a 11 anos. Enquanto isso, ocorre o inverso no que diz respeito à família extensa, que apresenta um percentual maior (27\%) na faixa etária de 10 a 11 anos, caindo para $14,3 \%$ na faixa etária de 06 a 07 anos. Isto pode indicar que nos primeiros anos do casamento as famílias se mantêm no modelo nuclear, transformando-se em extensas ou outro tipo com a passagem do tempo. O percentual de famílias recasadas também aponta neste sentido, pois as faixas etárias de 08 a 09 e 10 a 11 anos respectivamente perfazem, juntas, um percentual superior $(29,8 \%)$ ao percentual apresentado na faixa de 06 a 07 anos $(14,3 \%)$.

Neder (2000) considera que não existe um tipopadrão de organização familiar e, portanto, as famílias das camadas populares, como é o caso das que foram investigadas nesta pesquisa, necessitam de pessoas dentro de seus lares, ajudando com seus filhos e muitas vezes, com a divisão das despesas da casa. Neste contexto, a família nuclear é, não raro, substituída pela família extensa, já que a solidariedade entre os parentes, e mesmo entre os vizinhos, é condição primordial para a sobrevivência dessas famílias em situações de carência financeira. Falando a respeito de sua família, uma de nossas entrevistadas diz: "Na medida do possível é uma família boa, tem aqueles pequenos atritos, mas é uma família que na hora do sufoco, todo mundo ajuda todo mundo. $\mathrm{Na}$ hora de uma necessidade, aquele que sempre tem procura ajudar aquele que não tem."

O percentual de famílias de recasados aponta para o conceito de "monogamia seriada" citado por Bilac (1995, p.53). A busca de novos parceiros quando uma união se dissolve pode ser, nesses casos, indício da procura por novos provedores ou, pelo menos, da procura por alguém com quem se possa contar para dividir as despesas e responsabilidades da casa. Mas, além dos fatores econômicos, há outros, que se somam a estes e contribuem para a dissolução das uniões, como conflitos e agressividade. Uma das entrevistadas diz: "Apanhava muito dos dois maridos que tive antigamente, um me batia e o outro além de me bater ainda arrumava mulheres. Tive um filho com cada um (...) hoje sou um pouco mais alegre com meu atual."

Durante o tempo em que se encontram sem um novo parceiro, estas mulheres cuidam sozinhas de seus filhos, caracterizando famílias monoparentais; porém, muitas vezes, voltam para suas famílias de origem, ou mesmo dividem a convivência com amigos ou vizinhos. Deste modo o conceito de família, para esta população, pode ser bem diverso daquele das demais camadas da população. Uma entrevistada que tem vários filhos, sendo cada um de pai diferente, falando a respeito de sua própria história de vida, nos dá uma idéia do significado de pai, para ela: "Eu chamava pai porque ele me criou desde pequena (...)" Pai é portanto, aquele que cria a criança.

O mesmo ocorre com o conceito de família. A esse respeito, outra entrevistada diz: "Minha família sou eu, minha mãe e meus irmãos. Só conheço minha mãe, não conheço meu pai, nem meu irmão. Eu fui criada por uma tia, esta tia eu chamo de mãe até agora. 
Não fui criada pela minha mãe verdadeira porque ela não teve condições de me criar, aí preferiu dar a esta senhora, que somos como parentes. Ela me criou desde novinha. Ela tem quatro filhos e eu a considero, minha mãe e eles, meus irmãos." Como podemos ver, são os laços de solidariedade que, de fato, contam na formação desses vínculos, e não os laços de sangue e/ou parentesco. Isto é confirmado pelos desenhosestórias das crianças. Uma das crianças de nosso estudo desenha duas casas e diz: "Eu tenho duas vós, uma que mora no J. e uma que mora aqui. Aqui é a casa da minha vó, que eu tô morando com ela."

Deste modo surgem também os casos de adoção. Nesta amostra esses casos se dão por morte dos pais das crianças, por abandono ou doação, motivadas pelo "reconhecimento" da mãe de sua impossibilidade em criar o filho, seja por condições econômicas seja por outras. Em geral, são os familiares que adotam as crianças, avós ou tios. Uma avó relata: "Temos cinco filhos, dois meus, só que um está preso, e três do meu atual marido (...) meu filho que está preso tem três filhos que eu crio, a mãe não quer nem saber deles, eu adotei, tomei de conta."

Quanto às temáticas que emergiram na análise da dinâmica destas famílias, foram: mulheres assumindo papéis centrais no seio familiar (60\% dos casos); flutuação no exercício dos papéis familiares $(50 \%$ dos casos); solidariedade entre os membros da família e da comunidade (50\% dos casos); conflitos, agressividade e uso de álcool ou outras drogas (90\% dos casos) e figuras masculinas fragilizadas (70\%).

Os dados mostram que a dinâmica da maioria dessas famílias está girando em torno das mulheres, isto é, as mulheres são figuras fortes e marcantes entre elas. Uma de nossas entrevistadas diz: "Eu assumo tudo em minha casa, divido um apartamento com uma prima minha solteira, só eu trabalho; tenho que pagar as contas e as despesas dos meus dois filhos, que é um pouco grande. Às vezes tenho que me virar em mil: levar menino na escola, trabalhar, fazer compras e ainda prestar atenção aos deveres da escola deles, pois meu marido, quer dizer, meu ex-marido mora em São Paulo e nem lembra que a gente existe."

Quando apontamos a presença forte e marcante das mulheres nestas famílias, não estamos nos referindo exclusivamente às mães, pois esta presença pode ser de uma avó, tia, etc. Outra entrevistada diz: "A gente (mãe e filha) mora com minha mãe e minha irmã, eu trabalho o dia todo e ela (filha) fica com a avó (...) Ela é criada mais pela tia e pela avó. Ela é mais apegada à avó que sempre faz tudo que ela quer e pode dar o carinho que eu não dou; não tenho tempo."
Nos desenhos das crianças isto aparece quando elas desenham a mãe em primeiro lugar, ou como uma figura maior que a (s) figura (s) masculina (s), ou, ainda, quase sempre junto à figura da criança-índice, isto é, a criança que está sendo investigada. É, também, freqüente a omissão da figura paterna; ou, quando desenhada, algumas vezes as estórias envolvem prisão, bebida, desemprego, etc.

A centralidade das mulheres se manifesta, entre outras formas, através dos cuidados dedicados às crianças, porém, agora acrescidos pelo papel de provedoras destas famílias, muitas vezes como únicas provedoras.

$\mathrm{O}$ fato de as mulheres desempenharem o papel de provedor dessas famílias vai além do que Bilac (1995) afirma a respeito da classe popular, ou seja, que esta está constantemente recorrendo ao trabalho feminino remunerado para se manter. Não se trata de complementar a renda familiar, mas de ser a única ou a principal mantenedora.

Em oposição, os homens aparecem de forma fragilizada. Esta fragilização pode se manifestar através do desemprego, envolvimento com a polícia, uso de drogas. Diz um de nossos entrevistados: "Bebo por tempo. Se eu beber dá fome em mim, aí vou para casa e como. Em alguns dias bebo muito, nos outros paro, com as drogas também. Fumei maconha, cheirei cocaína e tomei rupinol. Quando morava com a mãe de F. (criança), ainda curtia. Outro entrevistado diz: Não agüento mais minha mulher... a gente briga muito, aí bebo sempre que posso, mas sou louco pela minha filha e, por ela, às vezes a gente não briga e se entende."

Esta fragilização das figuras masculinas também aparece nos desenhos-estórias das crianças. Uma das crianças, ao falar sobre seu desenho, conta a estória de um pai que está preso e de um tio que levou um tiro. Diz ainda que o filho mora com a mãe e a avó. Outra criança conta a seguinte estória: "O pai levou um tiro e foi para o hospital. Tá todo mundo chorando."

$\mathrm{O}$ desemprego é outro agravante; se associa à bebida e contribui para a deterioração da imagem masculina nestas famílias. Uma mãe diz: "Trabalho em casa de família e ele está desempregado faz mais de um ano. Às vezes é que aparece alguma coisa de pedreiro, de consertos e aí ele faz, está se virando; o que me preocupa é quando ele bebe."

Como vemos, associado ao baixo nível socioeconômico se encontra o alto nível de desemprego, que, em nosso meio, ocorre principalmente com a população masculina. Em vista dessa realidade, há necessidade de uma maior inserção da mulher no mercado de trabalho. Normalmente ela 
consegue serviço como doméstica ou diarista. Assim, em muitos casos, a mãe mantém sua família sozinha e à custa de passar o dia todo distante dos filhos, quando não os leva consigo para o trabalho, iniciando a criança no trabalho infantil: "Minha filha às vezes me ajuda onde eu trabalho, meus patrões são muito bons e dão coisas a ela." Ainda acerca do trabalho infantil outra mãe relata: "Minha filha trabalha, ela ajuda uma vizinha, ajuda ela pra ganhar um trocadinho."

Quanto ao desempenho dos papéis familiares, observamos que não há uma delimitação clara no exercício das funções, e sim, uma flutuação na ocupação desses lugares; ou seja, o pai, a mãe ou uma avó podem exercer tanto o papel do provedor quanto os cuidados e dedicação de afetos. Um dos pais diz: "Ela (a criança) vai pro colégio de manhã, todo dia eu é que vou buscar ela, pois minha mulher está trabalhando."

Se considerarmos as contingências que cercam essas famílias, fica fácil compreender que nem sempre o homem pode exercer o papel do provedor ou a mãe o papel afetivo. Há famílias em que o papel do provedor é exercido pela mãe, pela avó ou mesmo por um tio ou tia, uma vez que o pai está desempregado. Há também aquelas em que o papel afetivo é desempenhado por uma madrinha ou tia, uma vez que a mãe, necessitando trabalhar, pouco convive com a criança. Uma de nossas entrevistadas era a tia da criança. Ela nos contou: "Ela (a criança) vive comigo, né? Porque a mãe trabalha e ela vive comigo. Quem a traz na escola sou eu. Vive eu, minha mãe, meu esposo e meus dois filhos. A mãe dela mora juntinho, coladinho mesmo, mora com o marido dela."

Em geral, os cuidados com as crianças são compartilhados por todos. As crianças destas famílias não são de responsabilidade exclusiva do pai ou da mãe, mas também do irmão, de um tio, madrinha e até mesmo de vizinhos, o que acentua a tênue divisão entre a casa e a rua.

Isto também pode ser observado nos DesenhosEstórias das crianças. Uma das crianças conta em sua his(es)tória que são a avó e a mãe que criam seus primos. A mãe biológica morreu e as crianças foram adotadas pelos familiares paternos.

É interessante notar que, apesar desta flutuação nos papéis familiares, nos desenhos-estórias das crianças estes ainda aparecem relacionados ao sexo. Como exemplo, temos uma criança que conta a seguinte estória: "A mãe mandou a filha lavar os pratos, o pai foi trabalhar e o menino foi jogar bola. Outra diz: A mãe vai dar comida ao neném e o pai foi trabalhar. Mais uma afirma: A mãe vai sair com as crianças e o pai foi arrumar um emprego." Isto pode ser um indicador de que o ideal de família que ainda prevalece é o tradicional, mesmo que no concreto essas funções necessitem ser compartilhadas.

Essas funções compartilhadas remetem a um sentimento de solidariedade entre essas famílias. Mais uma vez nossos dados apontam na direção dos estudos de Bilac (1995), quando essa autora afirma que esse sentimento de solidariedade faz parte de uma estratégia de sobrevivência que caracteriza bem a ação da família perante a sociedade. Tios e madrinhas ajudam a tomar conta das crianças para que seus pais possam trabalhar e manter a família, ou até contribuem financeiramente para a manutenção da casa. "A gente mora com a minha mãe, eu trabalho e ela (a criança) fica com a avó (...) ela é mais criada pela tia e pela avó." Essa lógica da solidariedade reordena valores e subordina realizações pessoais a interesses e necessidades do grupo.

Bilac (1995) diz também que a solidariedade não pode ser entendida como sinônimo de harmonia e consenso entre os membros da família, e que este fato pode ser percebido através da violência e agressividade, muito comum nessas famílias. Nossos dados confirmam os achados de Bilac (1995). Encontramos a presença de álcool, conflitos e agressividade nestas famílias, porém estes fatores são minimizados e percebidos como coisas do cotidiano. Um dos entrevistados, que já havia relatado o uso de álcool com uma certa freqüência e intensidade, diz: "Eu com minha esposa, apesar de não estarmos bem, o relacionamento da gente é bom. Eu pedi um tempo pra ela se acalmar, e com os meninos é a mesma coisa, relacionamento de pai e mãe é normal, não tem agressividade. Ela faz a parte dela como mãe e eu como pai."

A agressividade não foi relatada por nossos entrevistados na sua forma mais extrema, a da violência física. Uma mãe diz: "Sou casada, mas estou me separando, a gente sempre deixa fora, não arenga na frente deles" (os filhos). O valor de não brigar na presença das crianças parece indicar a influência do modelo burguês de família. Os pais procuram deixar as crianças fora dos seus conflitos conjugais e evitam discutir na frente delas. Uma entrevistada diz: "Em relação a mim e meu esposo, a gente tenta não ter desavenças, já por causa deles (os filhos). Meu marido é temperamental, aí quando ele (o filho) vê o pai com o tom de voz mais alto, ele faz: pronto já tão brigando, painho e mainha. Ás vezes a gente tá, mas disfarça que não, né! A gente tenta levar o máximo que pode para não complicar a cabecinha deles (...)"

A idéia, hoje tão difundida na sociedade, de que não se deve traumatizar os filhos, que é vista por 
autores como Sérvulo Figueira (1985), Nicolaci-daCosta (1985) como uma psicologização do cotidiano, aparece nas falas dos entrevistados. $\mathrm{O}$ casal não briga na frente dos filhos "para não complicar a cabecinha deles."

É interessante observar que, apesar de o relato dos adultos não revelar violências físicas, é freqüente, nas estórias das crianças, surgirem relatos envolvendo polícia, tiros, prisão, etc. Isto indica que, mesmo que este tipo de violência não ocorra no interior da família, ela se encontra próxima do cotidiano destas crianças.

Enfim, o que se observa, de modo geral, é que estas famílias têm, ainda hoje, seu imaginário permeado por valores ligados a uma perspectiva de família tradicional; porém, no cotidiano vivido por elas, estes ideais necessitam ser freqüentemente adequados à realidade, de modo a garantir-lhes a sobrevivência.

\section{CONCLUSÕES}

Pelo que vimos, há uma diversidade de arranjos familiares entre os nossos pesquisados, ainda que se verifique o predomínio do modelo de família nuclear. Este modelo apresenta-se, com maior freqüência, nas famílias de crianças de uma faixa etária menor, o que nos faz pensar que, à medida que aumenta a idade das crianças e o número de anos de convivência do casal, iniciam-se as separações, ou ainda outros membros da família se juntam ao casal, dando origem às famílias monoparentais, de recasados e extensas. A presença de famílias adotivas é relativamente pequena nesta amostra, e quase sempre os casos se referem à adoção por parentes, tios ou avós. Conflitos, agressividade, uso de drogas e/ou álcool apresentam-se na maioria dos casos, mas são percebidos por essas famílias como expressões do cotidiano, não sendo enfatizados ou valorizados pelos nossos pesquisados. Em uma parte significativa dos casos, há a centralização das figuras femininas nestas famílias. Estas são figuras-chave dentro do âmbito familiar. Em contrapartida, as figuras masculinas aparecem bastante fragilizadas. Isto pode se manifestar através do desemprego, envolvimento com polícia, uso de drogas ou, ainda, pouco ou nenhum envolvimento com a família. $\mathrm{O}$ desemprego tem mais peso para essa fragilização do que os demais fatores. Há flutuação no exercício dos papéis familiares, tanto no que diz respeito à manutenção da família quanto aos cuidados e afetos dedicados às crianças. A presença da solidariedade entre os membros da família e da comunidade é muito comum nessas famílias, e foi expressa, nas mais das vezes, no compartilhar dos cuidados com as crianças. Tios, madrinhas, avós e até vizinhos tomam conta das crianças para que os pais possam trabalhar. Eles também ajudam financeiramente. Há casos em que mãe e filhos moram com os pais (avós da criança) e a mãe não trabalha, sendo todos sustentados por aqueles. A solidariedade é uma forma de enfrentar a condição social, é uma estratégia de sobrevivência.

\section{REFERÊNCIAS}

Ariès, P. (1978) História social da criança e da família. Rio de Janeiro: LTC - Livros Técnicos e Científicos Editora S.A.

Berthoud, C.M.E. (1997) Conversando sobre o método. Em C. M. O.Cerveny (Org.), Família e ciclo vital: nossa realidade em pesquisa. (pp.137-147). São Paulo: Casa do Psicólogo.

Bilac, E. D. (1995) Sobre as transformações nas estruturas familiares no Brasil: notas muito preliminares. Em I. Ribeiro \& A. C. Ribeiro (Orgs.). Famílias em processos contemporâneos: inovações culturais na sociedade brasileira (pp. 43-61). São Paulo: Edições Loyolas.

Duarte, L.F.D. (1995). Horizontes do indivíduo e da ética no crepúsculo da família. Em I. Ribeiro \& A. C. Ribeiro (Orgs.). Famílias em processos contemporâneos: inovações culturais na sociedade brasileira (pp.27-41). São Paulo: Edições Loyolas.

Figueira, S. A. (1985). Modernização da família e desorientação: uma das raízes do psicologismo no Brasil. Em S. A. Figueira (Org.) Cultura da psicanálise (pp. 142146) Rio de Janeiro: Jorge Zahar Editor.

Freitas, N. K. (1999). O emprego do genograma no estudo do processo do luto materno. Em T. Féres Carneiro (Org), Casal e família: entre a tradição e a transformação. (pp. 174-193) Rio de Janeiro: NAU.

Giddens, A.(2000) $O$ mundo em descontrole: o que a globalização está fazendo de nós. Rio de Janeiro: Record.

Lasch, C. (1991) Refúgio num mundo sem coração - A família: santuário ou instituição sitiada? Rio de Janeiro: Paz e Terra.

Neder, G. (2000) Ajustando o foco das lentes: um novo olhar sobre a organização das famílias no Brasil. Em, S. M., Kaloustian (Org.) Família brasileira: a base de tudo. (pp.26-46) São Paulo/ Brasília : Cortez/ UNICEF.

Nicolaci-da-Costa, A. M. (1985) Mal-estar na família: descontinuidade e conflito entre sistemas simbólicos. Em S. A. Figueira (Org.) Cultura da psicanálise (pp.147-168) São Paulo: Editora Brasiliense S. A.

Poster, M. (1979). Teoria crítica da família. Rio de Janeiro: Zahar Editores.

Quintas, F. (2000) A mulher e a família no final do século XX. Recife: Fundação Joaquim Nabuco/Editora Massangana.

Sarti, C. A. (1995) O valor da família para os pobres. Em I. Ribeiro \& A. C. Ribeiro (Orgs.), Famílias em processos contemporâneos: inovações culturais na sociedade brasileira (pp.131-150) São Paulo: Edições Loyolas.

Sarti, C. A. (2003) A família como espelho: um estudo sobre a moral dos pobres. São Paulo: Cortez. 
Silveira, S. C. da, Falcke, D. \& Wagner, A. (2000). A representação gráfica de meninos institucionalizados. Anais do $2^{\circ}$ Congresso da Sociedade Brasileira de Rorschach $e$ outros métodos projetivos (pp.232-240). Porto Alegre.

Trinca, W. (1997) Formas de investigação clínica em psicologia: procedimentos de desenhos-estórias:

Recebido em 23/01/2003 Revisado em 10/08/2003 procedimento de desenho de família com estórias. São Aceito em 30/08/2003 